\title{
A LINGUAGEM E SEU CARÁTER INSTITUCIONAL: REFLEXÔES SOBRE O DOMÍNIO DISCURSIVO JURÍDICO
}

\author{
THE LANGUAGE AND ITS INSTITUTIONAL CHARACTER: \\ REFLECTIONS ON THE LEGAL DISCOURSE DOMAIN
}

Maysa de Pádua Teixeira PAULINELLI ${ }^{1}$

\begin{abstract}
Resumo: Neste artigo, interessa-nos refletir sobre as práticas de linguagem no vasto território convencionalmente denominado domínio discursivo jurídico, discutindo as complexas relações entre linguagem, instituição e realização de ações nessa esfera de atividade humana. Partimos de fundamentações teóricas elaboradas em campos diferentes de investigação, como a Sociologia dos Campos, a Análise do Discurso e a Pragmática, a fim de compreender a dinâmica linguísticodiscursiva que caracteriza o referido domínio, tomando como fio condutor do raciocínio a questão do complexo institucional articulado à performatividade da palavra. Concluímos que um processo judicial é construído pelo trabalho dos sujeitos processuais, que são pessoas investidas de um estatuto institucional que Ihes confere a prerrogativa de participar ativamente de um caso de interação judiciária. Esse trabalho consiste em produzir textos nos moldes prescritos pela legislação. Cada um desses textos é composto por atos de fala que, proferidos pela pessoa autorizada, nas condições apropriadas, articulam-se na criação de um gênero textual, que passa a compor o repertório de quem o elaborou. Ao circularem, tais repertórios individuais compõem um sistema de atividades e, atuando harmonicamente entre si, produzem alterações na realidade social.
\end{abstract}

Palavras-chave: Linguagem. Instituição. Domínio discursivo jurídico.

\begin{abstract}
This paper presents a reflection on the language practices in the broad territory conventionally denominated legal discourse domain, discussing the complex relations between language, institution and accomplishment of actions in this human activity sphere. We start from theoretical foundations elaborated in different fields of research, such as the Fields Sociology, Discourse Analysis and Pragmatics, in order to understand the dynamics of the discourse language, which characterize the mentioned domain, having as a reasoning thread the question of the institutional complex articulated to the word's performativity. We conclude that a judicial process is built by the work of the procedural subjects, who are persons vested with an institutional statute that gives them the prerogative to actively participate in a case of judicial interaction. This work consists of producing texts along the lines prescribed by the legislation. Each of these texts is composed of speech acts that, given by the authorized person and under the appropriate conditions, are articulated in the creation of a textual genre, which now composes the repertoire of the author. When circulating, such individual repertoires make up a system of activities and, acting in harmony with one another, produce changes in social reality.
\end{abstract}

Keywords: Language. Institution. Legal discourse domain.

1 Paulinelli. UNIFESSPA. E-mail: maysapadua@unifesspa.edu.br. ORCID ID: https://orcid.org/0000-00029066-1720. 
- | A linguagem e seu caráter institucional: reflexões sobre o domínio discursivo jurídico

\section{Introdução}

Neste artigo, interessa-nos refletir sobre as práticas de linguagem no vasto território convencionalmente denominado domínio discursivo jurídico, discutindo as complexas relações entre linguagem, instituição e realização de ações nessa esfera de atividade humana. Partiu-se de fundamentações teóricas elaboradas em campos diferentes de investigação, como a Sociologia dos Campos, a Análise do Discurso e a Pragmática, a fim de compreender a dinâmica linguístico-discursiva que caracteriza o referido domínio. Trata-se de uma abordagem relevante e, ao mesmo tempo, desafiadora, uma vez que os pesquisadores acabam circunscrevendo seus objetos de estudo no âmbito daquilo que chamam de "discurso político", "discurso jurídico", "científico", "publicitário", "jornalístico", "literário", "religioso", "filosófico", que constituem noções muito difusas, que não caracterizam algo que se domina teoricamente (MENDES, 2008).

Tomando como ponto de partida a Sociologia dos Campos, cujo expoente mais ilustre é Pierre Bourdieu (2008), apresentamos a hipótese de que a força ilocucionária das palavras não pode ser encontrada nelas mesmas, ou seja, a eficácia da palavra não está em sua substância propriamente linguística, mas na adequação entre a função social do locutor e seu discurso. Em outros termos, a eficácia da palavra não depende do que ela enuncia, mas daquele que a enuncia e do poder do qual o enunciador está investido aos olhos do público. Destaca-se aqui a relevância do estatuto pessoal dos sujeitos, assim como da autoridade institucional usufruída por eles (autoridade individual e institucional do orador - a reputação de sua família, seu estatuto social, o que se sabe de seu modo de vida) para se alcançar uma finalidade por meio do discurso.

Adentrando o campo de investigações da Análise do Discurso, refletimos sobre a visão defendida por Maingueneau (1997), segundo a qual os estudos discursivos teriam equivocadamente privilegiado a análise dos diversos corpora sem levar em conta os atos de enunciação que os tornaram possíveis, como se tais atos fossem apenas um conjunto de "unidades destacáveis" e não uma dimensão constitutiva do discurso. Como sintomático dessa forma de pensar, a noção de instituição receberia nas Ciências da Linguagem uma interpretação restritiva, que se aplicava apenas à língua, e não ao discurso. Em sentido diverso, esse autor propõe-se a rearticular a questão da cena enunciativa e, ao mesmo tempo, aprofundar a discussão sobre o caráter institucional da atividade discursiva - a linguagem como ação institucionalizada - abordando o complexo institucional associado à enunciação de qualquer discurso.

Finalmente, encontramos em Searle (1995c, 1976) a hipótese de que as regras dos atos de fala, assim como as regras de um jogo, têm natureza constitutiva. Nessa 
construção teórica alicerçada na Filosofia da Linguagem, considera-se que a linguagem é uma forma de comportamento intencional regido por regras, as quais são da mesma ordem das regras de uma partida de futebol: aquelas são responsáveis pelas regularidades apresentadas na linguagem, enquanto estas dão conta das regularidades apresentadas em uma disputa futebolística. Essa hipótese prevê o papel das instituições como pressuposto necessário para que as regras adquiram sentido. Encontramos, ainda, em Searle (1976), a questão do estatuto dos interlocutores relacionada à força ilocucionária de um ato de fala ou condições preparatórias para que este ato seja desempenhado com sucesso.

Nas seções que compõem o presente artigo, aprofundamos a discussão sobre as relações entre linguagem, discurso e instituições na perspectiva de Bourdieu, Maingueneau, Amossy e Searle, tomando como fio condutor do raciocínio a questão do complexo institucional articulado à performatividade da palavra. Paralelamente, como nosso foco está voltado para a caracterização do domínio discursivo jurídico, apresentamos ensaios de aplicação dos aspectos teóricos discutidos à análise de um processo judicial instaurado pelo Ministério Público em face de uma mulher, acusada de ter praticado crime de autoaborto.

\section{Pressupostos teóricos}

\section{Bourdieu e a Sociologia dos Campos}

De maneira sintética, as incursões de Bourdieu pelas Ciências da Linguagem parecem ter se desenvolvido como uma reação à linguística de procedência saussuriana, cuja preocupação estruturalista teria gerado uma ruptura entre o estudo da língua e suas condições sociais de produção, reprodução e circulação, acarretando, com isso, uma busca estéril pelo poder da palavra na própria palavra.

Segundo Bourdieu (2008), esse poder estaria em uma posição exterior ao verbo, na medida em que as trocas simbólicas não se reduzem à relação de mera comunicação de conteúdos, ou seja, falar não é somente transmitir uma informação. Quem fala quer ser ouvido, obedecido, respeitado e, para isso, deve ocupar na estrutura social determinada posição que garanta à sua alocução o atributo de legitimidade.

Para Bourdieu (2008), não se pode explicar linguisticamente o princípio da lógica e da eficácia da linguagem institucional, desprezando o fato de que a autoridade de que se reveste a linguagem "vem de fora", é exterior ao orador. Dessa forma, parece claro que o autor desloca para o campo da autoridade a discussão acerca do poder da palavra. Em 
- | A linguagem e seu caráter institucional: reflexões sobre o domínio discursivo jurídico

outros termos, a eficácia das manifestações performativas seria um desdobramento de um poder que reside nas condições institucionais de sua produção e recepção. Eficácia equivaleria, assim, a uma questão de autoridade. E uma característica fundamental do discurso de autoridade é a necessidade de reconhecimento.

A explicação para a possibilidade de um sujeito agir mediante palavras em relação a outros sujeitos encontrar-se-ia, em última análise, no capital simbólico concentrado por ele, de forma que os locutores que detêm maior capital simbólico estão habilitados a impor as regras de produção e de aceitação das formas linguísticas tidas como adequadas.

Por fim, o autor entende que o reconhecimento implica, também, a cumplicidade por parte dos que se subordinam, devido à atuação dos mecanismos sociais capazes de produzir tal cumplicidade.

Ao refletirmos sobre o discurso jurídico, sobretudo quando enfocamos as condições enunciativas dos proferimentos produzidos nesse domínio, nos deparamos com essa problemática de considerar, ou não, o estatuto pessoal dos interlocutores como condição suficiente para o sucesso de determinados atos de fala por eles executados.

Se pensarmos como Bourdieu (2008), somos levados a assumir a hipótese de que a eficácia da palavra proferida por Juízes, Promotores, Advogados e outros operadores do Direito deriva do fato de estarem investidos de um estatuto social. Contudo, se nos situamos na perspectiva discursiva, nossa compreensão da questão da investidura caminha no sentido de se considerar que o estatuto é relevante, mas a legitimidade do locutor é construída também por meio de seu discurso. Em Maingueneau (1997) e Amossy (2006, 2005a, 2005b), encontramos a fundamentação para esse modo de pensar.

\section{O contraponto discursivo à Sociologia dos Campos}

Em uma perspectiva que alia Pragmática e Análise do Discurso, diferentemente do que propõe a Sociologia dos Campos, a eficácia da palavra é pesquisada no interior da troca verbal, relegando-se a um segundo plano os rituais exteriores à prática linguageira. Nesse domínio, interessam os dispositivos de enunciação, as relações entre um dizer, um dito e uma instituição, ou seja, a possibilidade de uma articulação entre linguagem e instituição, e não esta última considerada isoladamente. Em torno dessa possível articulação, destacamos os trabalhos de Maingueneau $(2008,1997)$ e de Amossy $(2006$, 2005a, 2005b).

Maingueneau (2008) direciona seus esforços na tentativa de articular - no nível do discurso - enunciado e enunciação, linguagem e contexto, fala e ação, instituição linguística 
e instituições sociais. Para isso, parte de um conceito fundamental que constitui a pedra angular de seu pensamento: o conceito de formação discursiva, tomado de empréstimo de Foucault (2012), em A Arqueologia do Saber. A partir desse conceito, Maingueneau (1997) estabelece, inclusive, a abrangência do termo "discurso" em sua teoria, que seria o conjunto de enunciados produzidos, a partir de certa posição, bem como o sistema de restrições que permite analisar as especificidades desta superfície discursiva.

Maingueneau pode ser incluído no rol dos que levam em consideração o complexo institucional como elemento de delimitação do discurso, tanto que, em seus trabalhos, propõe-se a reelaborar a questão da cena enunciativa e, ao mesmo tempo, aprofundar a discussão sobre o caráter institucional da atividade discursiva, tratando, assim, a linguagem como ação institucionalizada.

Na obra Gênese dos Discursos (2008), Maingueneau aborda a imbricação entre um discurso e uma instituição em termos de um sistema de restrições semânticas situadas além do enunciado e da enunciação. Trata-se de uma semântica global, responsável por restringir, em um determinado domínio discursivo, as temáticas abordadas, o vocabulário, as instâncias de enunciação, a intertextualidade. Esse sistema permitiria que os discursos fossem analisados juntamente com a rede institucional que a enunciação, a um só tempo, supõe e torna possível.

Maingueneau (2008) aponta, também, alguns fatores que podem auxiliar na identificação do funcionamento de um complexo institucional como um todo e seu interrelacionamento com a discursividade. Incluem-se aí o organograma de uma instituição, as regras que governam as instituições nas quais se desenvolve determinado discurso, sua organização espacial, o modo de enunciação de sua formação discursiva, o conteúdo dos proferimentos, o laço semântico essencial de um funcionamento institucional, os modos de difusão desenhados pela própria rede institucional.

Diante de suas constatações sobre a relação entre semântica do discurso e instituição, o autor é levado a se distanciar da concepção de instituição como "suporte" para enunciações, ou ainda, de um esquema fixo em que as instituições seriam a causa e o discurso, seu reflexo. Assumindo hipótese contrária, Maingueneau (2008, p. 128) afirma que as enunciações devem ser consideradas de acordo com a mesma dinâmica das instituições onde são produzidas, pois "a organização dos homens aparece como um discurso em ato, enquanto o discurso se desenvolve sobre as próprias categorias que estruturam essa organização".

O modo como Maingueneau (2005) compreende as relações entre discurso e instituição apresenta desdobramentos, também, para seus estudos sobre gêneros e sobre 
- | A linguagem e seu caráter institucional: reflexões sobre o domínio discursivo jurídico

ethos. Observa-se uma passagem da concepção que identifica os gêneros segundo suas características formais e adota-se uma concepção institucional, na qual forma e condições de enunciação se fundem.

Ainda sob o ponto de vista de Maingueneau (1997), um gênero discursivo sujeitase a condições de natureza comunicacional e de natureza estatutária. As condições comunicacionais são aquelas relacionadas à forma oral ou escrita, aos suportes e circuitos de difusão. As condições estatutárias, por sua vez, afinam-se com a questão da legitimidade do lugar que o enunciador ocupa no processo enunciativo, ou o tipo de estatuto que o enunciador genérico deve assumir para tornar-se sujeito de seu discurso.

Nesse ponto, a colocação de Bourdieu (2008) de que a eficácia da palavra é uma questão de autoridade é deslocada para o plano da enunciação. Diferentemente do sociólogo, Maingueneau (2008) entende que os próprios enunciadores definem seu "estatuto" e seu "modo de enunciação", inscrevendo a si e a seus enunciatários em uma certa posição social, marcando sua relação com um determinado saber e legitimando sua fala. Parece claro que, para Maingueneau (1997, 2005, 2008), esse fenômeno tem lugar no próprio discurso, pois o discurso é o lugar onde ocorre a atribuição de estatutos.

No mesmo sentido, Amossy (2005a, 2005b, 2006) aborda a eficácia da palavra por meio da articulação entre discurso, especialmente na modalidade argumentativa, e complexo institucional. A autora reconhece o valor, no dispositivo enunciativo, do estatuto do locutor e do quadro institucional no qual ele profere sua palavra, por entender que tal dispositivo depende também da posição daquele que detém a palavra e do grau de legitimação de que goza no espaço social onde circula. Nesse contexto, o ethos surgiria como componente essencial da eficácia da palavra, relacionando-se ao estatuto do locutor, mas encontrando sua legitimidade no discurso.

No tópico seguinte, apresentamos um outro olhar possível para essas discussões.

\section{A dimensão institucional na perspectiva da construção da realidade social}

Uma outra forma possível de abordagem da dimensão institucional de qualquer domínio discursivo pode ser pensada com base na teoria da construção da realidade social, no âmbito da Filosofia da Linguagem (SEARLE, 1995b). Em analogia ao pensamento de Searle, pode-se entender que o domínio discursivo jurídico é caracterizado pelo relacionamento dos fatos institucionais que o constituem.

Os fatos institucionais são para o autor uma subcategoria especial dos fatos sociais. Fato social é qualquer fato que envolva intencionalidade coletiva. Os fatos institucionais, 
além da intencionalidade coletiva, requerem instituições humanas especiais para sua existência, primordialmente, a linguagem. Os fatos sociais e sua subcategoria existem em oposição aos fatos brutos, que não dependem de quaisquer instituições para existirem, nem mesmo da instituição da linguagem, e precisam dela apenas para que possam ser declarados.

A realidade social, que está intrinsecamente associada à existência de uma comunidade que partilha um conjunto de crenças, de valores ou de bens simbólicos, é criada por um dispositivo de produção de fatos institucionais, ao qual Searle (1995b) denomina "poderosa máquina de geração de realidade social". O funcionamento dessa "máquina" apoia-se em um movimento contínuo e próprio do universo humano, no qual os sujeitos, por meio da intencionalidade coletiva, atribuem funções a objetos ou fenômenos que não as possuem previamente, criando, com isso, um fato novo - um fato institucional - que só existe e se mantém em virtude do consenso humano.

A intencionalidade coletiva é um fenômeno biologicamente primitivo, que de forma alguma pode ser reduzido à somatória de intencionalidades individuais. O elemento crucial na intencionalidade coletiva é o senso de fazer (querer, acreditar, etc.) algo juntos, e a intencionalidade individual, que cada pessoa tem, é derivada da intencionalidade coletiva de que todos partilham.

O papel por ela desempenhado nesse processo de criação da realidade social é tão importante que a própria definição de fato social, segundo Searle, está atrelada à intencionalidade coletiva. Para o autor, qualquer fato que envolva intencionalidade coletiva é um fato social. E ainda: "a forma mais simples de fatos sociais envolve formas simples de intencionalidade coletiva." (SEARLE, 1995b, p. 37, tradução nossa).

A respeito do segundo componente do aparato de construção de fatos institucionais - a imposição de funções a entidades - Searle (1995b) explica que é uma característica própria de seres conscientes a capacidade de atribuir funções a objetos e outros fenômenos que, por suas propriedades, não possuem tais funções. O autor ressalta que essas funções nunca são intrínsecas e que são atribuídas relativamente aos interesses dos usuários.

O elemento chave na criação de fatos institucionais seria, então, a imposição de um estatuto coletivamente reconhecido a uma entidade cuja estrutura física é apenas arbitrariamente relacionada ao desempenho da função. Trata-se do movimento de atribuição de "funções-estatuto". Como ilustração, Searle (1995b) lembra o caso do dinheiro, especialmente a evolução da moeda corrente em papel. 
- | A linguagem e seu caráter institucional: reflexões sobre o domínio discursivo jurídico

Esse movimento de atribuição de funções-estatuto a determinadas entidades é representado pela forma geral " $X$ (fato bruto) vale como $Y$ (função-estatuto atribuída por intencionalidade coletiva) em $C$ (contexto que se traduz pela rede integrada de relações com outros fatos institucionais)". Em outras palavras, o termo $X$ é um objeto ou fenômeno que se torna $Y$, ao receber determinadas funções por via da imposição coletiva, em um contexto C, ressaltando-se, mais uma vez, que o estatuto e a função que o acompanha vão além das puras funções físicas brutas que podem ser atribuídas a $X$.

Para exemplificar a atuação de regras constitutivas de fatos institucionais no domínio jurídico, podemos pensar em uma situação em que $X$ (pedaço de papel com certos caracteres) vale como $\mathrm{Y}$ (resumo de uma decisão judicial produzida por um colegiado de juízes ou, simplesmente, Súmula) em um contexto C (Justiça brasileira).

O autor acrescenta, ainda, que a forma de atribuição de uma nova função-estatuto, que, como já se afirmou, pode ser representada pela fórmula " $\mathrm{X}$ conta como $Y$ em C", em algumas situações, adquire uma configuração política, razão pela qual a fórmula ganha status normativo. Isso é demonstrado pelo fato de que a regra geral cria a possibilidade de abusos que não podem existir sem a regra, sendo que essa possibilidade de abuso é característica de fatos institucionais.

Outra informação relevante é a de que a atribuição de função-estatuto pode ser desdobrada de maneira iterativa, ou seja, podem ser atribuídas novas funções a objetos que já tinham alguma outra função. No exemplo apresentado acima, podemos pensar que aquela súmula agora é $X$ e que, por meio do movimento de imposição de funções-estatuto, transforma-se em Y (uma "Súmula vinculante") no mesmo contexto C, da Justiça brasileira. A esse respeito, Mendes (2008) complementa que "essas funções reiteradas historicamente podem formar sistemas complexos de estruturas imbricadas e hierarquizadas, através do tempo".

As chamadas "Súmulas vinculantes" configuram-se como atos de linguagem produzidos por julgadores no interior de processos judiciais, que fazem parte do gênero discursivo Acórdão e que, no contexto institucional da Justiça brasileira, adquirem foros de lei, passando a vincular, ou obrigar, a decisão dos juízes de primeira instância como se lei fossem. Convém enfatizar que, apesar de vincular como lei, a súmula é produzida por um Poder que, no sistema de Direito adotado pelo Brasil, não tem entre suas atribuições a faculdade de legislar, por isso esse instituto tem gerado grande polêmica em meio aos estudiosos do Direito pátrio.

O autor chama a atenção para a postura dos sujeitos diante da realidade social, afirmando que a atitude que nós temos diante do fenômeno é em parte constitutiva do 
fenômeno. Acreditar que "algo é algo": essa é uma característica notável dos fatos sociais, que não encontra análogo entre os fatos físicos. Não obstante, o processo de criação de fatos institucionais pode ocorrer sem que os participantes estejam conscientes de que isso está acontecendo de acordo com a fórmula canônica. Primeiro, porque nós nascemos e crescemos em uma sociedade e recebemos suas instituições. Segundo, porque os participantes não precisam estar conscientemente atentos quanto à forma de intencionalidade coletiva pela qual eles estão impondo funções a objetos.

Outro ponto a ser ressaltado é o de que existe uma relação especial entre imposição de funções-estatuto e linguagem, e essa relação é tão estreita que se afirma que o elemento linguístico é parte constitutiva dos fatos institucionais. Em outras palavras, a linguagem aparece como fator essencial não apenas para a representação desses fatos, mas para sua criação e manutenção. A título de ilustração, o autor mais uma vez apresenta o exemplo do dinheiro: as etiquetas que são partes da expressão $\mathrm{Y}$, como a etiqueta "dinheiro", agora são parcialmente constitutivas do fato criado (SEARLE, 1995b). Desse modo, um grande número de fatos institucionais pode ser criado pela explicitação de proferimentos performativos (declarativos).

A linguagem desempenha, ainda, outros papéis no quadro dos fatos institucionais, pois a complexidade das instituições sociais requer linguagem para sua representação e comunicabilidade, pois, sendo os fatos inerentemente sociais, devem ser comunicáveis. E a linguagem é um meio de comunicação pública por excelência.

\section{Análise de uma dinâmica de interação judicial: o Processo Penal em uma visão sistêmico-institucional}

A fim de ilustrar as reflexões teóricas aqui elaboradas, propomos a análise de um caso concreto de interação judicial, consistente na análise dos autos de um processo criminal instaurado contra uma mulher, acusada de ter praticado o crime de autoaborto ${ }^{2}$.

Com base em Mendes (2008), podemos afirmar que as relações entre os fatos institucionais do discurso jurídico se materializam em níveis, mais ou menos profundos, de busca de consenso pragmático, a saber: a) o nível inferior, que compõe os atos de fala; b) o nível intermediário, de que fazem parte os gêneros do discurso e c) o nível superior, do domínio discursivo.

2 De acordo com a Denúncia do Promotor de Justiça, a ré teria introduzido uma sonda em seu útero para
interromper uma gestação de dois ou três meses, infringindo, assim, o artigo 124 do Código Penal Brasileiro. 
- | A linguagem e seu caráter institucional: reflexões sobre o domínio discursivo jurídico

Articulando esses três níveis de consenso pragmático, assumimos a hipótese de que os atos de fala definem e designam os gêneros discursivos, além de contribuírem para sua orientação argumentativa; cada sujeito processual, em uma situação de interação linguageira travada nos limites de um processo judicial, produz conjuntos de gêneros no desempenho de suas atividades profissionais; diversos conjuntos de gêneros se articulam para a formação de sistemas de gêneros que, por sua vez, compõem um domínio discursivo e realizam fatos sociais. Com isso, chegamos à seguinte representação:

\section{HIPÓTESE EXPLICATIVA}

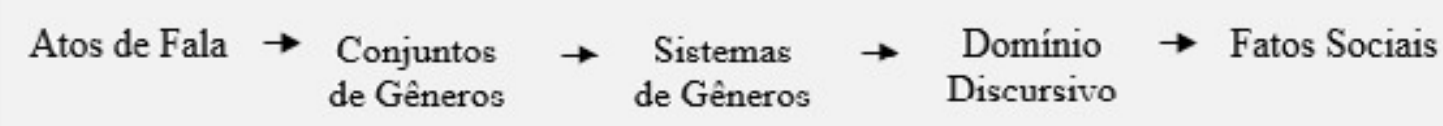

Figura 1. Hipótese explicativa do funcionamento do domínio discursivo jurídico

Fonte: Elaboração própria

Para essa análise, adotamos os seguintes procedimentos metodológicos:

a) O primeiro passo foi fazer um levantamento de todos os sujeitos que atuaram no Processo, indicando os gêneros utilizados por cada um deles para a realização dos atos processuais. Esse procedimento nos possibilitou identificar o conjunto de gêneros de cada sujeito processual;

b) Em um segundo momento, buscou-se investigar como esses conjuntos de gêneros vão se entrelaçar para constituir um sistema de gêneros e, nessa qualidade, produzir fatos sociais, provocando alterações na realidade social.

Os procedimentos sugeridos por essa metodologia implicam a resposta às seguintes perguntas: quais sujeitos atuaram no processo penal selecionado? Que gêneros cada sujeito utilizou para executar seu papel no processo? Que atividades os textos produzidos por esses sujeitos ajudaram a realizar? Que fatos sociais emergem da atuação articulada de conjuntos de gêneros diversos?

Em seguida, apresentamos possíveis respostas a esses questionamentos.

\section{Os sujeitos processuais e seus conjuntos de gêneros}

Os fatos sociais produzidos pela utilização de gêneros emergem tanto de conjuntos de gêneros como de sistemas de gêneros (BAZERMAN, 2005). 
Os conjuntos de gêneros são a coleção de textos produzidos por um sujeito no desempenho de um determinado papel social. O estudo de um conjunto de gêneros permite que sejam catalogadas a extensão do trabalho, a habilidade de articulação e a competência de um determinado profissional. Entende-se, com isso, que um conjunto de gêneros é aferido, tomando-se o locutor/agente como o parâmetro da classificação, o que implica a observação de que cada especialista realiza determinadas ações tipificadas na instituição jurídica, as quais são mais facilmente textualizadas, quando se conhece o gênero apropriado para sua efetivação no meio escrito (FUZER; BARROS, 2008).

O Juiz, o Promotor de Justiça e o Defensor/acusado são considerados sujeitos principais da relação jurídico-processual. Ao longo da demanda analisada, esses sujeitos principais praticaram uma série de atos e produziram inúmeros documentos.

O Juiz, por exemplo, produziu, ao longo do processo, vários despachos e ofícios, um edital de convocação do Júri, um mandado para notificação de jurados, um termo de verificação de cédulas (digitado por uma auxiliar da justiça e assinado por ele), uma decisão de pronúncia da ré e uma sentença que extinguiu o processo. Esses documentos compõem, assim, o conjunto de gêneros produzido pela instância julgadora e aferem qual a função desempenhada por ela na aplicação da justiça penal, que é a de prover a regularidade do processo, determinando o que deve ser feito pelos auxiliares da justiça, bem como manter a ordem das audiências, das sessões ou diligências, além da função precípua de decidir.

O Promotor de Justiça produziu Denúncia, Alegações Finais do Ministério Público, Contra-razões Recursais do Ministério Público, Libelo-Crime Acusatório, pedido de prisão preventiva e debates orais na sessão de julgamento, além de declarações, requerimentos e pareceres. Emerge daí o conjunto de gêneros do Promotor de Justiça, bem como a função que desempenha no Processo Penal: a doutrina o considera parte e "senhor da ação", por ser ele fiscal da aplicação da lei e, ao mesmo tempo, responsável pela atividade de acusação do réu.

O Defensor, que representa a voz do réu no processo, produziu Defesa Prévia, Alegações Finais, petição de interposição de recurso em sentido estrito, Razões Recursais, debates orais na sessão de julgamento, declarações.

No exercício da função jurisdicional, o Juiz conta com a colaboração de outros agentes no que se relaciona à atividade de documentação e de execução dos atos processuais. São os chamados auxiliares da justiça, que atuam para tornar a relação jurídico-processual concreta, promovendo andamento prático ao feito, executando atividades técnicas e burocráticas que vão dar materialidade ao Processo Penal. A doutrina 
- | A linguagem e seu caráter institucional: reflexões sobre o domínio discursivo jurídico

os classifica como partes acessórias do processo. São eles: o Distribuidor, que registra e distribui os feitos entre as Secretarias; o Escrivão ou chefe da Secretaria para onde o feito é remetido e os escreventes, que são seus auxiliares; o Oficial de Justiça, que executa os mandados de citação, intimação, busca e apreensão, diligências, prisão, etc.; os auxiliares de cartório, que se incumbem dos protocolos, entregas de autos, etc. (MIRABETE, 2001).

Fuzer e Barros (2008) lembram que alguns gêneros, no interior de um Processo Penal, só podem ser utilizados por um determinado sujeito processual. No mesmo sentido, Travaglia (2002) afirma que, em quadros institucionais rígidos, existem os "produtores esperados" de certos tipos de textos. Assim, o Relatório de Inquérito só pode ser produzido/assinado pelo Delegado de Polícia que investigou o caso, da mesma forma que a Denúncia só pode ser produzida/assinada pelo Promotor de Justiça e a sentença, pelo Juiz que preside o processo. Outros gêneros, como despachos e ofícios, são de domínio menos restrito e podem ser produzidos tanto pelo Juiz, pelo Delegado de Polícia e pelo Promotor.

\section{Os sistemas de gêneros}

Diversos conjuntos de gêneros utilizados por pessoas que trabalham juntas de forma organizada compõem um sistema de gêneros. Um sistema de gêneros organiza o trabalho discursivo, as relações sociais e a circulação de gêneros no interior de uma instituição. Parece que o critério utilizado para se caracterizar um sistema de gêneros não é mais o agente, como no conjunto de gêneros, mas a relação de interdependência que existe entre as produções discursivas, que lhes dá a configuração de uma rede. A análise dos sistemas permite que essa interdependência ou intertextualidade seja colocada à mostra.

O esquema a seguir representa os principais atos que se verificaram no Processo/ corpus, assim como os principais documentos produzidos pelos sujeitos processuais: 


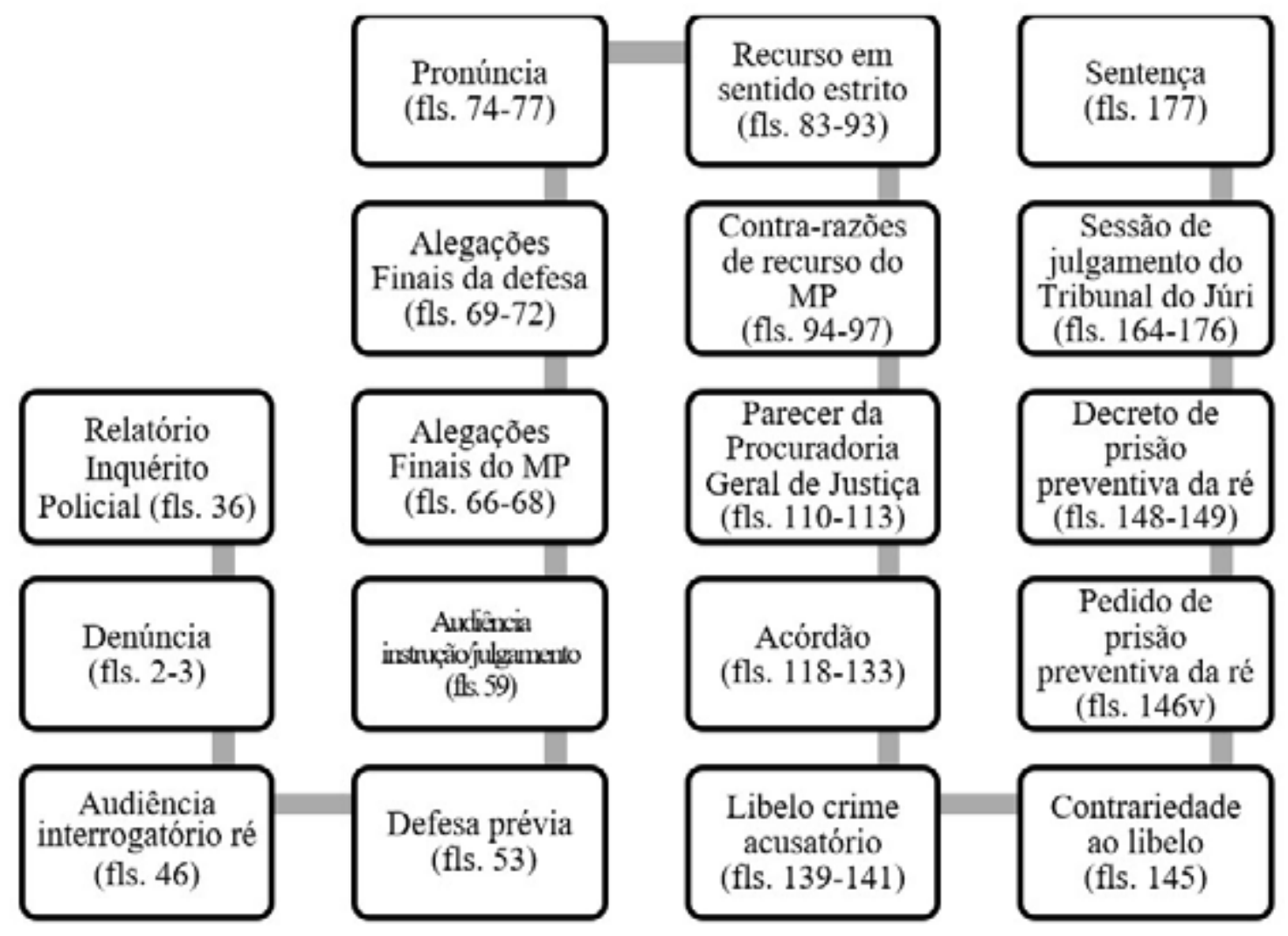

Figura 2. Esquema representando os principais atos e documentos produzidos no

Processo/corpus

Fonte: Elaboração própria

Observamos que nessa rede onde se imbricam conjuntos de gêneros produzidos por vários sujeitos processuais, um ato ou documento não poderia ser produzido sem que outro o fosse previamente. Existe uma forte relação de interdependência entre as práticas, regulamentada pela legislação processual penal.

Assim, o Inquérito Policial, cujo responsável é o Delegado de Polícia, auxiliado pela Polícia Civil e Militar, é pré-requisito para que o Promotor de Justiça possa apresentar a Denúncia. Com fundamento nos fatos narrados e nas provas produzidas nesse inquérito é que o Promotor a redige. Entretanto, por regulamentação legal, a Denúncia é acostada como a primeira peça do processo e o Inquérito Policial, autuado na sequência, acaba desempenhando o papel de um anexo da Denúncia, ao qual o Promotor de Justiça faz referências a todo momento, citando trechos, documentos, depoimentos compilados ali.

Desse modo, a Denúncia é a primeira peça encartada, apesar de não ter sido a primeira a ser produzida. Ocorre que os documentos não são autuados necessariamente 
- | A linguagem e seu caráter institucional: reflexões sobre o domínio discursivo jurídico

na ordem cronológica em que são produzidos, mas em uma ordem prescrita pelo Código de Processo Penal, que garante a aplicação concreta do princípio do contraditório: primeiro se manifesta a acusação, depois, a defesa.

A Defesa Prévia da ré, oferecida pelo Defensor, só pode ser produzida após o interrogatório. O Código prescreve a realização de uma audiência de instrução e julgamento, na qual são ouvidas as testemunhas e, supostamente, esclarecidos os fatos que levaram a ré a ser processada.

Somente após essa audiência, o Promotor tem condições de oferecer as Alegações Finais da Acusação, porque, nessa peça, ele faz uma revisão geral do processo, comentando as provas, articulando argumentos, para encerrar com o pedido de condenação da ré.

Em refutação aos argumentos do Promotor, o Defensor apresenta as Alegações Finais da Defesa, construindo sua argumentação com base em fatos e provas que permitam a ele encerrar pedindo a absolvição da ré. As alegações do Promotor são autuadas anteriormente às alegações do Defensor para que, ao elaborar sua peça, este tenha ciência do conteúdo de toda a acusação, e assim possa contrariá-la amplamente, em respeito ao princípio do contraditório e da ampla defesa.

É que, norteando o Processo Penal, existem alguns princípios que tentam tornar a relação entre o Estado, que é o órgão detentor da persecução penal, e o réu um pouco menos desequilibrada, ao conceder a este (a parte mais fraca) algumas garantias de que não será sumariamente condenado, sem ao menos ter o direito de defesa ${ }^{3}$.

Com a Decisão de Pronúncia, o Juiz decide pelo menos sobre esse primeiro conflito instaurado no processo. Dessa forma, o Processo Penal pode ser considerado um sistema de gêneros, uma vez que os textos que constituem seus autos não podem ser analisados isoladamente; eles fazem parte de uma rede constituída de outros textos, que ajudam a realizar atividades específicas que competem aos participantes do sistema. Esses participantes - os operadores do Direito - fazem uso de uma série de documentos que podem ser reconhecidos por funções e formas específicas, configurando-se em gêneros discursivos que se inter-relacionam para se alcançar um fim.

3 A esse respeito, abrimos um parêntese para lembrar a situação surreal vivida pelo personagem Joseph K., na obra O Processo, de Kafka. O personagem se vê como réu em um processo sobre o qual não lhe é informado sequer o conteúdo da acusação, o órgão acusatório, o tribunal em que será realizado o julgamento. Enfim, a trama criada por Kafka nos faz sentir o caos que viveríamos sem a segurança do devido processo legal. 


\section{Os domínios discursivos e a realização de fatos sociais}

Bazerman (2005, p. 146) postula que a organização do trabalho discursivo e das relações sociais no interior de um domínio, por meio dos sistemas de gêneros, é vista de forma muito nítida nos discursos jurídicos processuais, em que "[...] o trabalho todo é realizado no desenrolar de uma série de textos e enunciados; todos os recursos externos, para se tornarem relevantes aos procedimentos jurídicos, precisam ser incorporados na sequência de enunciados por um processo de tradução e avaliação.".

Essa afirmação é corroborada por uma máxima vigente no direito, segundo a qual "o que não está nos autos não está no mundo", o que implica dizer que o Juiz deve julgar uma causa, levando em conta apenas o que está materializado nos autos; todos os recursos externos, se não carreados ao feito, devem ser ignorados pelo julgador.

O autor reforça, também, o papel das regulamentações nesse sistema, lembrando que os textos aí produzidos têm de estar em consonância com o que prescreve a ordem jurídica, com suas leis, instituições e precedentes, que definem o desenrolar intertextual dos enunciados. Comentando os trabalhos de Engeström (1992), Bazerman (2005, p. 132) afirma que:

Nos casos em que a tarefa é produzir discurso, tal como a produção de um discurso judicial - cujo objetivo é tornar claras e responsabilizáveis todas as ações desenvolvidas em apoio às decisões tomadas num processo judicial -, a organização processual e formal, através da qual emerge o discurso, tanto modela o produto discursivo final como enquadra a participação de cada pessoa no tribunal.

De fato, existem, por um lado, as normas processuais penais que determinam o rito a ser seguido para a apuração do crime como, por exemplo, no Código de Processo Penal está escrito que os crimes dolosos contra a vida são de competência do Tribunal do Júri. Por outro lado, existem as normas de organização judiciária, que regulamentam detalhadamente o andamento do feito nas Secretarias. Assim, o trabalho de um auxiliar da justiça, consistente em proceder à juntada de documentos, abrir vistas a uma e outra parte, fazer os autos conclusos ao juiz, redigir documentos (como mandados de citação) e digitar termos de depoimentos, está rigidamente previsto em normas de organização judiciária. 
- A linguagem e seu caráter institucional: reflexões sobre o domínio discursivo jurídico

\section{Considerações finais}

Ao abordar as relações entre linguagem e instituição, colocando esta última como realidade exterior àquela, Bourdieu (2008) dirige, assim, seu foco de análise para as condições institucionais a serem preenchidas, a fim de que um discurso de autoridade seja reconhecido. Mais ainda, a discussão é encaminhada para as condições a serem preenchidas para que a própria instituição funcione.

Ao refletirmos sobre o discurso jurídico, sobretudo quando enfocamos as condições enunciativas dos proferimentos produzidos nesse domínio, nos deparamos com essa problemática de considerar, ou não, o estatuto pessoal dos interlocutores como condição suficiente para o sucesso de determinados atos de fala por eles executados. Se pensarmos como Bourdieu (2008), somos levados a assumir a hipótese de que a eficácia da palavra proferida por Juízes, Promotores, Advogados e outros operadores do Direito deriva do fato de estarem investidos de um estatuto social. Contudo, se nos situamos na perspectiva discursiva, nossa compreensão da questão da investidura caminha no sentido de se considerar que o estatuto é relevante, mas a legitimidade do locutor é construída também por meio de seu discurso. Em Maingueneau (1997) e Amossy (2006, 2005a, 2005b), encontramos a fundamentação para esse modo de pensar que nos parece o mais convincente.

Tecidas as considerações teóricas que sustentaram nosso pensamento, partimos para a demonstração de como se engendram as relações entre linguagem, performatividade e instituição, a partir da análise de um processo criminal instaurado para apuração de suposto crime de autoaborto, evidenciando, com isso, características peculiares do domínio discursivo jurídico.

Concluímos, ao final, que um Processo Penal é construído pelo trabalho dos sujeitos processuais, que são pessoas investidas de um estatuto institucional que lhes confere a prerrogativa de participar ativamente de um caso de interação judiciária como o aqui investigado. Esse trabalho consiste em produzir textos nos moldes prescritos pela legislação. Cada um desses textos é composto por atos de fala que, proferidos pela pessoa autorizada e nas condições apropriadas, articulam-se na criação de um gênero textual, que passa a compor o repertório de quem o elaborou. Esses repertórios individuais, colocados em circulação, compõem um sistema de atividades e, atuando harmonicamente entre si, produzem alterações na realidade social. 


\section{Referências}

AMOSSY, R. L'argumentation dans le discours. Paris: Armand Colin, 2006.

AMOSSY, R. (org.). Imagens de si no discurso: a construção do ethos. Tradução Dílson Ferreira da Cruz et al. São Paulo: Contexto, 2005a.

AMOSSY, R. Rhétorique et analyse du discours. Pour une approche socio-discursive des textes. In: ADAM, J.-M.; HEIDMANN, U. Sciences du texte et analyse de discours. Etudes de Lettres, 2005b.

BAZERMAN, C. Gêneros textuais, tipificação e interação. São Paulo: Cortez, 2005.

BOURDIEU, P. A economia das trocas lingüísticas: o que falar quer dizer. 2. ed. Tradução Sergio Miceli et al. São Paulo: Editora da Universidade de São Paulo, 2008.

ENGESTRÖM, Y. Interactive Expertise: studies in distributed working intelligence. Helsinki: Department of Education, 1992.

FOUCAULT, M. A Arqueologia do Saber. 8. ed. Tradução Luiz Felipe Baeta Neves. São Paulo: Forense Universitária, 2012.

FUZER, C.; BARROS, N. Processo Penal como sistema de gêneros. Revista Linguagem em (Dis)curso, v. 8, n. 1, p. 43-64, jan./abr. 2008.

MAINGUENEAU, D. Novas tendências em Análise do Discurso. 3. ed. Tradução Freda Indursky. Campinas: Pontes: Editora da UNICAMP, 1997.

MAINGUENEAU, D. Ethos, cenografia, incorporação. In: AMOSSY, R. (org.). Imagens de si no discurso: a construção do ethos. Tradução Dílson Ferreira da Cruz et al. São Paulo: Contexto, 2005. p. 69-92.

MAINGUENEAU, D. Gênese dos discursos. Tradução Sírio Possenti. São Paulo: Parábola Editorial, 2008.

MARI, H. Atos de Fala: Notas sobre origens, fundamentos e estrutura. In: MARI, H. et al. (org.). Análise do Discurso: fundamentos e práticas. Belo Horizonte: NAD/FALE/UFMG, 2001. p. 93-131. 
- | A linguagem e seu caráter institucional: reflexões sobre o domínio discursivo jurídico

MENDES, P. H. A. Fatos institucionais e discurso político. Conferência apresentada no III SIMPÓSIO INTERNACIONAL SOBRE ANÁLISE DO DISCURSO - Emoções, ethos e argumentação, Universidade Federal de Minas Gerais, Belo Horizonte, 2008. [CD-ROM].

MIRABETE, J. F. Processo Penal. 13. ed. São Paulo: Atlas, 2001.

SEARLE, J. R. Expressão e significado: estudos da teoria dos atos de fala. São Paulo: Martins Fontes, 1995a.

SEARLE, J. R. Intencionalidade. Tradução Julio Fischer e Tomás Rosa Bueno. São Paulo: Martins Fontes, 1995b.

SEARLE, J. R. The construction of social reality. Nova York: Free Press, 1995c.

SEARLE, J. R.; VANDERVEKEN, D. Foundations of illocutionary logic. Cambridge: Cambridge University Press, 1983.

SEARLE, J. R. Speech acts: an essay in the philosophy of language. Londres: Cambridge University Press, 1976.

TRAVAGLIA, L. C. Gêneros de texto definidos por atos de fala. In: ZANDWAIS, A. (org.). Relações entre pragmática e enunciação. Porto Alegre: Sagra Luzzato, 2002. p. 129-153.

COMO CITAR ESTE ARTIGO: PAULINELLI, Maysa de Pádua Teixeira. A linguagem e seu caráter institucional: reflexões sobre o domínio discursivo jurídico. Revista do GEL, v. 16, n. 2, p. 145-162, 2019. Disponível em: https://revistadogel.gel.org. $\mathrm{br} /$

DOI: http://dx.doi.org/10.21165/gel.v16i2.2687

Submetido em: 19/09/2019 | Aceito em: 05/12/2019. 